\title{
Synthesis of (-)-julocrotine and a diversity oriented Ugi-approach to analogues and probes
}

\author{
Ricardo A. W. Neves Filho ${ }^{1}$, Bernhard Westermann ${ }^{1,2}$ \\ and Ludger A. Wessjohann ${ }^{* 1,2, \S}$
}

\section{Full Research Paper}

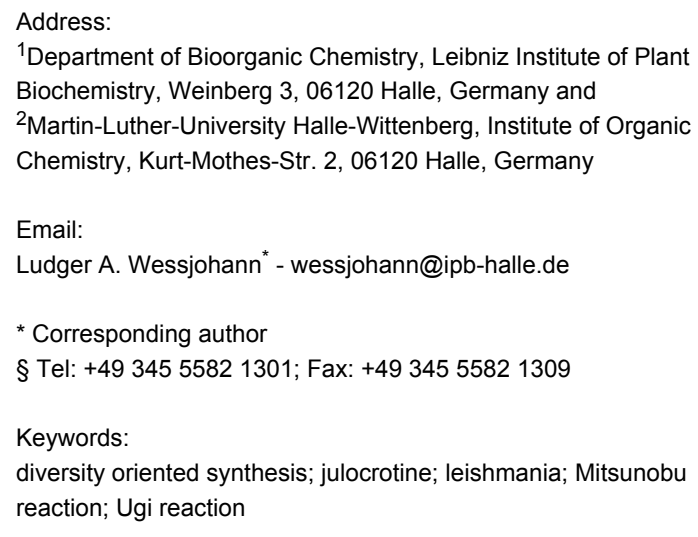

\author{
Beilstein J. Org. Chem. 2011, 7, 1504-1507. \\ doi:10.3762/bjoc.7.175 \\ Received: 01 September 2011 \\ Accepted: 21 October 2011 \\ Published: 07 November 2011 \\ Guest Editor: T. J. J. Müller \\ (C) 2011 Neves Filho et al; licensee Beilstein-Institut. \\ License and terms: see end of document.
}

This article is part of the Thematic Series "Multicomponent reactions".

\begin{abstract}
An improved total synthesis of (-)-julocrotine in three steps from Cbz-glutamine, in $51 \%$ overall yield, is presented. To demonstrate the potential of the heterocyclic moiety for diversity oriented synthesis, a series of (-)-julocrotine analogues was synthesized by employing the heterocyclic precursor as an amino input in Ugi four-component reactions (Ugi-4CR) [1].
\end{abstract}

\section{Introduction}

Julocrotine (1) is a natural glutarimide alkaloid isolated from several plants of the genus Croton [2-4], including Croton cuneatus Klotzsch, which is used by Amazonia natives in antiinflammatory and analgesic medicines. The structure of this glutarimide-containing alkaloid was first proposed in 1960, based upon a series of degradative experiments, but only confirmed in 2008 by X-ray analysis [5-7]. Most interestingly, it was found to inhibit the growth of promastigote and amastigote forms of the protozoan Leishmania amazonensis (L.) with no cytotoxicity against the host cell [8]. This parasite causes cutaneous leishmaniasis, a neglected disease that affects more than 12 million people in tropical countries [9].
In addition, the glutarimide motif can be considered as a privileged structure. Compounds with this pharmacophore often exhibit a wide range of biological properties including anti-inflammatory [10], antitumor [11,12], and anticonvulsive properties [13].

Because of the low yields of julocrotine obtained through isolation from natural sources and the necessity to gain access to larger quantities of this substance for further biological screening, Silva and Joussef developed a straightforward total synthesis in six steps [14]. Starting from L-glutamic acid, their chiral-pool approach yielded the desired optically active natural 
product in $41 \%$ overall yield. After analyzing the structure of $(-)$-julocrotine, we set out to synthesize it in only three steps from commercially available L-Cbz-glutamine, in a sequence of cyclization (a), N-alkylation (b), and the removal of the protecting group followed by acylation with $(S)$-2-methylbutanoic acid (c) [15] (Figure 1).

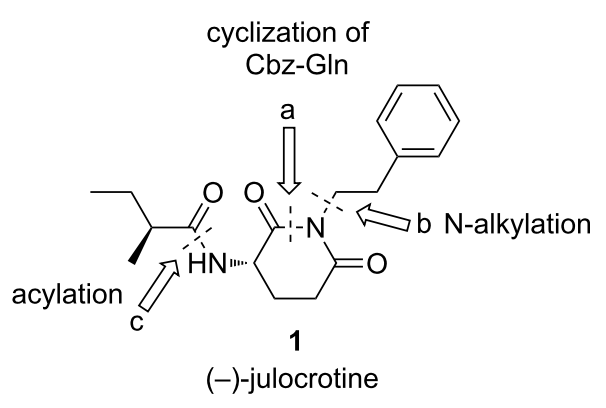

Figure 1: Retrosynthetic scheme for (-)-julocrotine (1).

Based on this flexible route, we also envisioned the synthesis of derivatives utilizing post-cyclization transformations by multicomponent reactions. This diversity-driven approach benefits from the fact that the heterocyclic moiety may be considered a privileged structural element for bioactivity.

\section{Results and Discussion}

The synthetic approach, illustrated in Scheme 1, starts from Cbz-glutamine 2, which reacted in the presence of dicyclohexylcarbodiimide (DCC) and $N$-hydroxysuccinimide (NHS) in DMF to afford Cbz-glutarimide $\mathbf{3}$ in $76 \%$ yield in optically pure form [16]. To alkylate the imide-moiety, glutarimide 3 was reacted with phenylethyl bromide in the presence of potassium carbonate at room temperature. The desired compound 4 was obtained in $98 \%$ isolated yield, but analysis revealed racemization. Indeed, the equilibration at the chiral center of $\mathbf{4}$ can be observed even in the presence of weak bases such as potassium carbonate [17]. Thus, we decided to use a base-free N-alkylation protocol, namely the Mitsunobu reaction of $\mathbf{3}$ and the readily available 2 -phenylethanol [18]. This protocol gave the desired optically active product in $90 \%$ yield $\left([\alpha]^{20} \mathrm{D}-29.2\right)$. The key intermediate 4 was hydrogenated on $\mathrm{Pd} / \mathrm{C}$ at room temperature to afford $\mathbf{5}$, which was coupled with $(S)$-2methylbutanoic acid in the presence of EDCl and HOBt to afford (-)-julocrotine (1) in 73\% yield, over two steps. The HRMS, ${ }^{1} \mathrm{H}$ and ${ }^{13} \mathrm{C}$ NMR spectra, optical rotation, and melting point of 1 were consistent with the reported data [2,14,15].

For the diversity oriented synthesis the advanced intermediate $\mathbf{5}$ was used as the amino component in an Ugi-4CR with $(S)$-2methylbutanoic acid, hydrophobic amino acids, formaldehyde

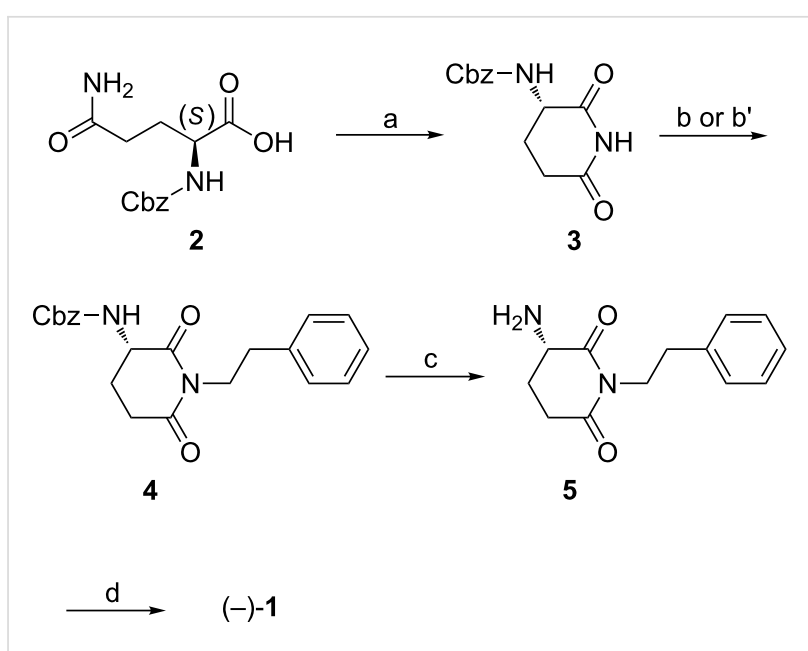

Scheme 1: Reactions and conditions: (a) DCC, NHS, DMF $80^{\circ} \mathrm{C}$, $18 \mathrm{~h}, 76 \%$. (b) $\mathrm{Ph}\left(\mathrm{CH}_{2}\right)_{2} \mathrm{Br}, \mathrm{K}_{2} \mathrm{CO}_{3}$, acetone, r.t., $20 \mathrm{~h}$, ( \pm )-4, $98 \%$. (b') $\mathrm{Ph}\left(\mathrm{CH}_{2}\right)_{2} \mathrm{OH}, \mathrm{DIAD}, \mathrm{PPh}_{3}$, THF, r.t., 20 h, (-)-4, $90 \%$. (c) $\mathrm{H}_{2}, 10 \%$ w/w $\mathrm{Pd} / \mathrm{C}, \mathrm{MeOH}$, r.t., $4 \mathrm{~h}$, quant. (d) (S)-2-methylbutanoic acid, EDCl, $\mathrm{HOBt}, \mathrm{CH}_{2} \mathrm{Cl}_{2}$, r.t., $16 \mathrm{~h}, 73 \%$.

and tert-butyl isocyanide (Scheme 2). These analogues possess a protease-resistant peptoid scaffold and this might lead to an enhanced activity $[19,20]$. In this endeavor, all Ugi reactions were initiated by pre-imine formation of $\mathbf{5}$ and reaction with formaldehyde as the oxo-component, after which the multicom-

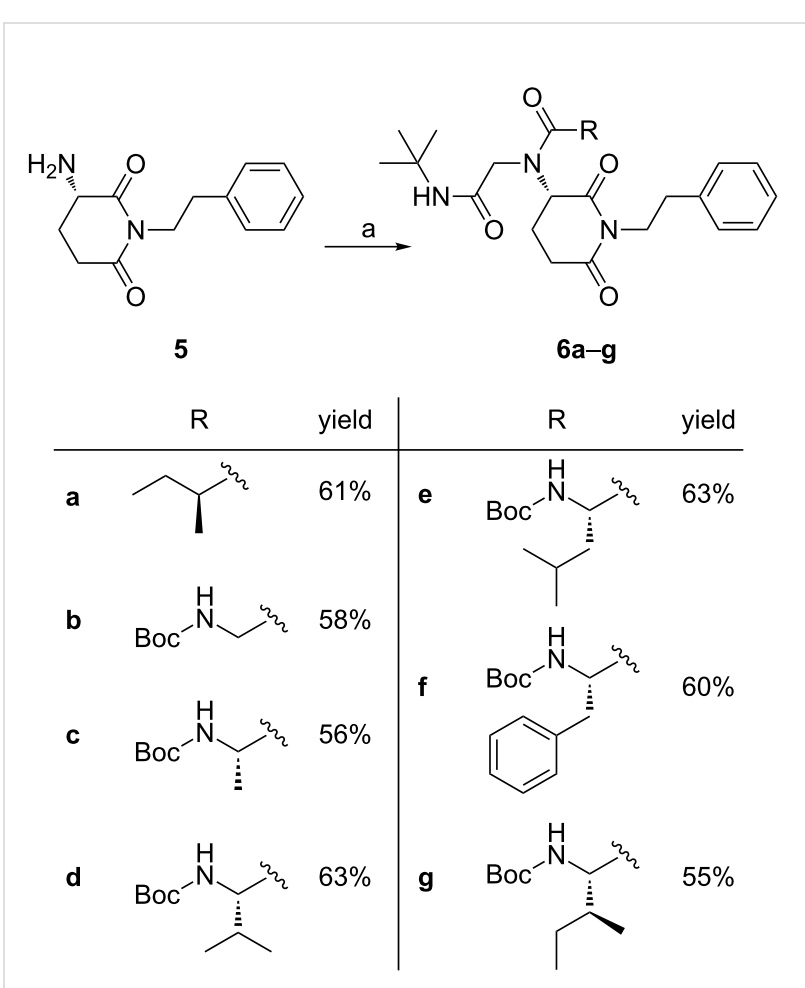

Scheme 2: Reactions and conditions: (a) $\left(\mathrm{CH}_{2} \mathrm{O}\right)_{n}, \mathrm{MeOH}$, r.t., $2 \mathrm{~h}$ then, $\mathrm{RCOOH}$ and $t-\mathrm{BuNC}$, r.t., $18 \mathrm{~h}$. 
ponent reaction was completed by the addition of $(S)$-2methylbutanoic acid, Boc-Gly, Boc-Ala, Boc-Val, Boc-Leu, Boc-Phe and Boc-Ile and tert-butyl isocyanide. Following this procedure, the desired optically active compounds $\mathbf{6 a}-\mathbf{g}$ were obtained in $55-63 \%$ yields. Their structures were confirmed by ${ }^{1} \mathrm{H},{ }^{13} \mathrm{C}$ NMR and HRMS spectra.

Finally, the Ugi-4CR was utilized for the synthesis of a molecular probe prototype of $\mathbf{1}$, which can be used for intercalation studies (Scheme 3). For this propose, the natural product scaffold should be attached through a spacer to a reporter tag, which is normally a luminescent group or a dye. The advanced intermediate 5 was converted to the respective imine as depicted in Scheme 2 and then reacted with $(S)$-2-methylbutanoic acid and isonitrile 7 to afford the intermediate 8 in $61 \%$ yield. This compound was then hydrogenated to afford 9 and then directly coupled with 1-pyrenemethylamine, by using EDCl as coupling reagent, to yield the designed probe prototype $\mathbf{1 0}$ in $80 \%$ yield (from 8).

Pyrene derivative $\mathbf{1 0}$ exhibited strong blue luminescence in both solution and solid phase. This probe may be used for tracking the (-)-julocrotine in biological systems, in particular in promastigote and amastigote forms of protozoan Leishmania amazonensis (L.). It could be helpful to elucidate the to-date unknown mode of action of this natural product in the parasite.

\section{Conclusion}

In summary, a highly efficient method to synthesize (-)julocrotine (1) in three steps from Cbz-glutamine 2 was developed. The approach affords the natural product in $51 \%$ overall yield. The versatility of the developed protocol was demonstrated in the synthesis of seven julocrotine analogues and a molecular probe utilizing Ugi-4CRs. The desired compounds $\mathbf{6 a}-\mathbf{g}$ and $\mathbf{1 0}$ were obtained in good yields.

\section{Supporting Information}

\section{Supporting Information File 1}

Experimental procedures and analytical data.

[http://www.beilstein-journals.org/bjoc/content/

supplementary/1860-5397-7-175-S1.pdf]

\section{Acknowledgements}

The authors thank Dr. Jürgen Schmidt and Mr. Torsten Geißler for the HRMS and emission spectra and Ms. Leah M. Harris for a kind revision of this manuscript. R.A.W.N.F. is grateful to CNPq for a Ph.D. fellowship.

\section{References}

1. Hulme, C.; Dietrich, J. Mol. Diversity 2009, 13, 195-207. doi:10.1007/s11030-009-9111-6

2. Anastasi, C. A. Asoc. Quim. Argent. 1925, 13, 348-356.

3. Aboagye, F. A.; Sam, G. H.; Massiot, G.; Lavaud, C. Fitoterapia 2000, 71, 461-462. doi:10.1016/S0367-326X(00)00141-6

4. Suárez, A. I.; Blanco, Z.; Delle Monache, F.; Compagnone, R. S.; Arvelo, F. Nat. Prod. Res. 2004, 18, 421-426. doi:10.1080/14786410310001622004

5. Nakano, T.; Djerassi, C.; Corral, R. A.; Orazi, O. O. Tetrahedron Lett. 1959, 1, 8-12. doi:10.1016/S0040-4039(01)99446-8

6. Nakano, T.; Djerassi, C.; Corral, R. A.; Orazi, O. O. J. Org. Chem. 1961, 26, 1184-1191. doi:10.1021/jo01063a051

7. Moreira, R. Y. O.; Brasil, D. S. B.; Alves, C. N.; Guilhon, G. M. S. P.; Santos, L. S.; Arruda, M. S. P.; Müller, A. H.; Barbosa, P. S.; Abreu, A. S.; Silva, E. O.; Rumjanek, V. M.; Souza, J., Jr.; da Silva, A. B. F.; de A. Santos, R. H. Int. J. Quantum Chem. 2008, 108, 513-520. doi:10.1002/qua.21355

8. Guimarães, L. R. C.; Rodrigues, A. P. D.; Marinho, P. S. B.; Müller, A. H.; Guilhon, G. M. S.; Santos, L. S.; do Nascimento, J. L. M.; Silva, E. O. Parasitol. Res. 2010, 107, 1075-1081. doi:10.1007/s00436-010-1973-0<smiles>CCC(C)C(=O)N(CC(=O)NCCCC(=O)NCOc1ccccc1)[C@H]1CCC(=O)N(CCc2ccccc2)C1=O</smiles> 
9. Leishmaniasis: The magnitude of the problem, World Health Organization.

http://www.who.int/leishmaniasis/burden/magnitude/burden_magnitude len/index.html (accessed July 25, 2011).

10. Michalska, D.; Morzyk, B.; Bienko, D. C.; Wojciechowski, W. Med. Hypotheses 2000, 54, 472-474. doi:10.1054/mehy.1999.0879

11. Matsuda, F.; Kawasaki, M.; Terashima, S. Tetrahedron Lett. 1985, 26 , 4639-4642. doi:10.1016/S0040-4039(00)98773-2

12. Choi, B.-G.; Seo, H.-K.; Chung, B.-H.; Choi, S.-U.; Lee, C.-O Arch. Pharmacal Res. 1994, 17, 467-469. doi:10.1007/BF02979127

13. Lee, J.; Son, K.; Kim, M.; Jung, G.; Choi, J.; Lee, E.-S.; Park, M. Arch. Pharmacal Res. 1999, 22, 491-495. doi:10.1007/BF02979158 And references cited therein.

14. Silva, L. L.; Joussef, A. C. J. Nat. Prod. 2011, 74, 1531-1534. doi:10.1021/np200234e

15. Teng, B.; Zheng, J.; Huang, H.; Huang, P. Chin. J. Chem. 2011, 29 , 1312-1318. doi:10.1002/cjoc.201180248 During the preparation of this manuscript the above mentioned article, applying a similar strategy for the synthesis of $(-)$-julocrotine, was published.

16. Kaldor, S. W.; Hammond, M.; Dressman, B. A.; Labus, J. M.; Chadwell, F. W.; Kline, A. D.; Heinz, B. A. Bioorg. Med. Chem. Lett. 1995, 5, 2021-2026. doi:10.1016/0960-894X(95)00345-T

17. Sondheimer, E.; Holley, R. W. J. Am. Chem. Soc. 1957, 79, 3767-3770. doi:10.1021/ja01571a041

18. Sen, S. E.; Roach, S. L. Synthesis 1995, 756-758. doi:10.1055/s-1995-4012

19. Miller, S. M.; Simon, R. J.; Ng, S.; Zuckermann, R. N.; Kerr, J. M.; Moos, W. H. Drug Dev. Res. 1995, 35, 20-32. doi:10.1002/ddr.430350105

20. Kreye, O.; Westermann, B.; Wessjohann, L. A. Synlett 2007, 3188-3192. doi:10.1055/s-2007-990912

\section{License and Terms}

This is an Open Access article under the terms of the Creative Commons Attribution License (http://creativecommons.org/licenses/by/2.0), which permits unrestricted use, distribution, and reproduction in any medium, provided the original work is properly cited.

The license is subject to the Beilstein Journal of Organic Chemistry terms and conditions:

(http://www.beilstein-journals.org/bjoc)

The definitive version of this article is the electronic one which can be found at: $\underline{\text { doi:10.3762/bjoc.7.175 }}$ 